\title{
Reduction of Mevalonate Pyrophosphate Decarboxylase in Mouse Melanoma Cells Treated with $\delta$-Tocotrienol Is Not Associated with Reduction of Cholesterol Content or Release of Lysosomes and Melanosomes
}

\author{
Akihiro Michihara, ${ }^{*}$ Mai Shimatani, Sachiyo Morita, and Kenji Akasaki \\ Faculty of Pharmacy and Pharmaceutical Sciences, Fukuyama University, Fukuyama, Hiroshima 729-0292, Japan \\ (Received January 14, 2010; Accepted February 13, 2010; Published online February 19, 2010)
}

We previously reported that a decrease in the melanin content of mouse melanoma cells (B16 cells) treated with $\delta$-tocotrienol was the result of a decrease in the level of tyrosinase activity and protein. Use of $\delta$-tocotrienol as a whitening agent, may therefore have side effects. In the present study, we examined whether $\delta$-tocotrienol caused side effects (the release of lysosomes from and a decrease in the cholesterol content of cells). We also examined the release of melanosomes (lysosome-related organella). Neither of lysosomes nor melanosomes were released from cells treated with $\delta$-tocotrienol, since $\beta$ glucuronidase (melanosomal and lysosomal enzyme) activity, melanin content (melanosomal marker), and tyrosinase (melanosomal enzyme) activity did not increase in the cell culture medium. Although mevalonate pyrophosphate decarboxylase (MPD; an enzyme of cholesterol biosynthesis) was significantly reduced in the cells treated with $\delta$-tocotrienol, cholesterol content was not. Thus, $\delta$-tocotrienol might be useful as a therapeutic or preventive drug for hyperpigmentation and as a component of whitening and/or lightening cosmetics not causing severe side effect (reduction of cholesterol content and release of lysosomes/melanosomes), although $\delta$-tocotrienol cause a decrease of MPD.

Key words — tocotrienol, tyrosinase, melanin, melanosome, cholesterol, mouse melanoma

\footnotetext{
*To whom correspondence should be addressed: Faculty of Pharmacy and Pharmaceutical Sciences, Fukuyama University, Fukuyama, Hiroshima 729-0292, Japan. Tel.: +81-84936-2111; Fax: +81-849-36-2024; E-mail: mitihara@fupharm. fukuyama-u.ac.jp
}

\section{INTRODUCTION}

Vitamin $\mathrm{E}$ is a generic term for eight naturally occurring forms of lipophilic compounds called tocopherols and tocotrienols. Tocopherols and tocotrienols share a polar chromanol ring that is linked to an isoprenoid-derived hydrocarbon side chain. Tocotrienols and tocopherols can be subdivided into four isomers $(\alpha, \beta, \gamma$, and $\delta)$ with regards to the numbers and position of methyl groups on their chromanol ring, and differ only in possessing a farnesyl or saturated phytyl side chain, respectively. ${ }^{1)}$ The nutritive value of tocopherols and tocotrienols in food products emanates from their well-known antioxidant capacity, which helps to prevent oxidative damage to polyunsaturated fatty acids. ${ }^{2}$ )

Tocotrienols, but not tocopherols, have been linked to additional beneficial therapeutic properties that include antithrombotic and neuroprotective activities and the ability to inhibit proliferation of breast cancer cells and lower serum cholesterol levels when administered in the diet of chickens, swine, rats, and hypercholesterolemic patients. ${ }^{3-9)}$ Early studies revealed an association between the hypocholesterolemic activity of tocotrienol-rich extracts and decreased levels of hepatic 3-hydroxy-3-methylglutaryl (HMG)CoA reductase (rate-limiting enzyme of cholesterol biosynthesis) activity. ${ }^{7)}$ Subsequent structureactivity studies revealed that $\delta$ - and $\gamma$-tocotrienols were the most potent suppressors of HMG-CoA reductase in primary rat hepatocytes and cultured $\mathrm{HepG}_{2}$ cells. ${ }^{10,11)}$ Furthermore, it was reported that $\delta$-tocotrienol stimulates ubiquitination and degradation of reductase and blocks processing of sterol regulatory element-binding proteins (SREBPs), an- 
other sterol-mediated action of Insigs. ${ }^{12)}$

We previously reported that the exocytosis of mature enzymes from lysosomes into the medium was caused by a lovastatin (HMG-CoA reductase inhibitor)- and/or lipoprotein-deficient serum (LDS)-induced decrease in the cholesterol content in B16F10 mouse melanoma cells. ${ }^{13)}$ Melanosomes contain several lysosomal enzymes such as $\beta$ glucuronidase, ${ }^{14,15)}$ suggesting that melanosomes are lysosome-related organelles. ${ }^{16)}$ Therefore, it was suggested that the release of not only lysosomes but also melanosomes was caused by the decrease in cholesterol content.

We previously reported that a decrease in the melanin content of mouse melanoma cells (B16 cells) treated with $\delta$-tocotrienol was the result of a decrease in the level of tyrosinase activity and protein. ${ }^{17)}$ Use of $\delta$-tocotrienol as a therapeutic or preventive drug for hyperpigmentation or as a component of whitening and/or lightening cosmetics, may result in the release of lysosomes or melanosomes from and a decrease in the cholesterol content of cells as side effects.

In the present study, we examined the effect of $\delta$-tocotrienol on the release of lysosomes and melanosomes into cell culture medium and the cholesterol content of cells.

\section{MATERIALS AND METHODS}

Materials — The $\delta$-tocotrienol was obtained from Eisai (Tokyo, Japan). Cholesterol E-test Wako kits from Wako (Osaka, Japan), Dulbecco's modified Eagle medium (D-MEM) was obtained from Gibco (Tokyo, Japan), B16 cells from RIKEN (Ibaraki, Japan), goat anti-lactate dehydrogenase (C-17) IgG from Santa Crutz Biotechnology, Inc. (Santa Crutz, CA, U.S.A.), rabbit anti-goat IgG conjugated to horseradish peroxidase from Invitrogen Corporation (San Clemente, CA, U.S.A.), goat anti-rabbit IgG conjugated to horseradish peroxidase from Invitrogen Corporation (Carlsbad, CA, U.S.A.). All other chemicals were of reagent grade, and purchased from various commercial sources.

Cultured Melanoma Cell Line-B16 cells were diluted to $1.5 \times 10^{6}$ per $35-\mathrm{mm}$ tissue culture dish with D-MEM containing $10 \%$ fetal bovine serum (FBS), and then incubated in humidified air containing $5 \% \mathrm{CO}_{2}$ at $37^{\circ} \mathrm{C}$ for $24 \mathrm{hr}$. In some experiments, the cells were shifted to D-MEM containing $10 \%$ FBS in the presence of $10-100 \mu \mathrm{M}$ $\delta$-tocotrienol [dissolved in $2 \mu 1$ dimethyl sulfoxide (DMSO)] for $24 \mathrm{hr}$.

Preparation of Sample — B 16 cells incubated on $35-\mathrm{mm}$ dishes were washed several times in cold D-MEM. On the day of the experiment, the medium was aspirated from the culture dishes, and cells were then washed twice with $1 \mathrm{ml}$ of ice-cold phosphate buffered saline (PBS). Next, $750 \mu \mathrm{l}$ of homogenate buffer containing $1 \%$ Triton X-100, $0.5 \mathrm{mM}$ phenylmethylsulfonyl fluolide (PMSF), $10 \mathrm{mM}$ 2-mercaptoethanol, $1 \mathrm{mM}$ EDTA, and protease inhibitors ( $1 \mu \mathrm{M}$ leupeptin, $1 \mu \mathrm{M}$ pepstatin $\mathrm{A}, 1 \mu \mathrm{M}$ chymostatin, and $1 \mu \mathrm{M}$ antipain) was added to the cells, which were then scraped off using a rubber policeman. The solution of B16 cells was homogenized with 5 strokes in a Teflon homogenizer. After centrifugation for $5 \mathrm{~min}$ at 1000 $\times g$, the post-nuclear supernatant (PNS) was used to assay $\beta$-glucronidase $(\beta-\mathrm{G})$ activity, to measure cholesterol content, and for immunoblotting.

Protein Assay — Protein levels were measured by the method of Lowry et al. using bovine serum albumin (BSA) as the standard. ${ }^{18)}$

$\boldsymbol{\beta}$-G Activity $\beta$ - $\mathrm{G}$ activity was assayed as described by Robins et al. ${ }^{19)}$

Tyrosinase Activity — Two hundred microliters of a $0.3 \%$ dopa solution was added to $100 \mu \mathrm{l}$ of PNS and incubated at $37^{\circ} \mathrm{C}$ for $20 \mathrm{~min}$. Tyrosinase activity was measured with a spectrophotometer at $475 \mathrm{~nm}^{20)}$

Melanin Content - Cells dissolved in $1 \mathrm{ml}$ of alkaline solution $(1 \mathrm{~N} \mathrm{NaOH})$ and incubated at $80^{\circ} \mathrm{C}$ for $2 \mathrm{hr}$ were used to measure levels of protein and melanin. The amount of melanin was measured with a spectrophotometer at $420 \mathrm{~nm} .^{21)}$

Cholesterol Content of Cells — Two hundred microliters of PNS was mixed with $5 \mathrm{ml}$ of Folch extract (chloroform [2] : methanol [1]), and the mixture was incubated for $10 \mathrm{~min}$ at $37^{\circ} \mathrm{C}$ with shaking. After the mixture was centrifuged at $3000 \times g$ for $10 \mathrm{~min}, 3 \mathrm{ml}$ of the supernatant was evaporated dry by boiling at $100^{\circ} \mathrm{C}$ and then dissolved in $200 \mu \mathrm{l}$ of isopropylalchol containing $1 \%$ Triton X-100. The cholesterol content of the solution was determined using the Cholesterol E-test Wako kit.

Sodium Dodecyl Sulfate-Polyacrylamide Gel Electrophoresis (SDS-PAGE) and Immunoblotting — SDS-PAGE was performed on $10 \%$ slab gels according to the method of Laemmli. ${ }^{22)}$ Proteins on the SDS-slab gel were transferred to a nylon membrane (NEN) by electrophoresis, using a modified version of the procedure of Towbin et al. ${ }^{23)}$ Pos- 
itive bands were visualized using ECL Western blotting detection kits (Amersham Pharmacia, Amersham, U.K.) that contained a sensitive chemiluminescent substrate for horseradish peroxidase.

Antibody Mevalonate Pyrophosphate Decarboxylase (MPD) — MPD was purified from rat liver, as described by Michihara et al., and a rabbit polyclonal antiserum raised against the rat MPD was used. ${ }^{24)}$

Statistics — The statistical analysis was carried out using Student's $t$-test. Data are presented as the mean \pm S.D.

\section{RESULTS}

Rate of Survival of Mouse Melanoma Cells Treated with $\delta$-Tocotrienol

We estimated the rate of survival of $\delta$ tocotrienol-treated and untreated cells by measuring the amount of protein and Lactate dehydrogenase (LDH). As shown in Fig. 1, the amount of protein and LDH in cells treated with $10-100 \mu \mathrm{M}$ $\delta$-tocotrienol for $24 \mathrm{hr}$ was similar to that in untreated cells. These results indicated that almost all $\delta$-tocotrienol-treated cells survived.

The Effect of $\delta$-Tocotrienol on the Release of $\boldsymbol{\beta}-\mathrm{G}$, Tyrosinase, and Melanin into the Medium

To examine whether $\delta$-tocotrienol caused the release of lysosomes or melanosomes from cells, we measured levels of $\beta-\mathrm{G}$ (a lysosomal and melanosomal enzyme) activity, melanin (a melanosomal marker), and tyrosinase (a melanosomal marker enzyme) activity in the culture medium of cells treated with 10,50 , or $100 \mu \mathrm{M} \delta$-tocotrienol. As shown in Fig. 2A, levels of $\beta$-G activity did not increase significantly in either the medium or cytoplasm of the treated cells (Fig. 2A). The melanin content inclined to increase in the medium of treated cells compared to that of untreated cells, but the difference was not significant (Fig. 2B). The melanin contents significantly decreased by 33 or $25 \%$ in cells, 22 or $15 \%$ in medium plus cells by treatment with 50 or $100 \mu \mathrm{M}$ $\delta$-tocotrienol, respectively, compared with the control cells. Tyrosinase activity in the medium did not decrease significantly (Fig. 2C). The tyrosinase activity significantly decreased by 34,42 or $58 \%$ in cells, 27,33 or $40 \%$ in medium plus cells by treatment with 10,50 or $100 \mu \mathrm{M} \delta$-tocotrienol, respectively, compared with the control cells. These results suggested that $\delta$-tocotrienol did not cause the

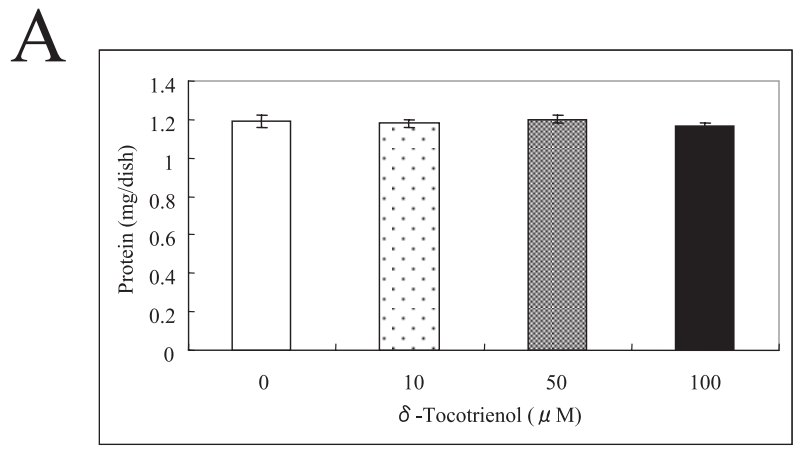

\section{B}
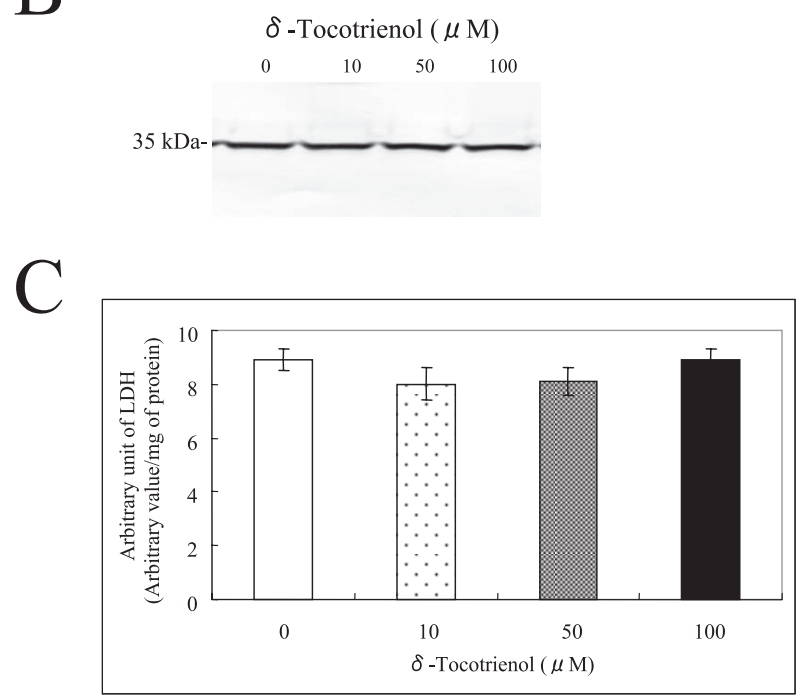

Fig. 1. Amount of Protein and LDH Activity in Cells Treated with $\delta$-Tocotrienol

B16 cells were cultured in the absence or presence of 10,50 , and $100 \mu \mathrm{M} \delta$-tocotrienol for $24 \mathrm{hr}$, and cells were homogenized with $750 \mu \mathrm{l}$ of homogenate buffer. After centrifugation at $1000 \times g$ for $5 \mathrm{~min}$, PNS was obtained. A: Protein contents in PNS were measured as described in Materials and Methods. B: PNS $(30 \mu \mathrm{g})$ was subjected to immunoblotting using anti-LDH antibody, and these signals were then measured using an Intelligent Quantifier. Data are the means of three identical experiments.

release of lysosomes or melanosomes, although it did cause a decrease in melanin contents and tyrosinase activity in cells as described previously.

The Effect of $\delta$-Tocotrienol on Cholesterol Biosynthetic Enzymes and Cholesterol Content in the Cell

To examine whether levels of enzymes involved in cholesterol biosynthesis other than HMG-CoA reductase decreased with $\delta$-tocotrienol treatment, the amount of MPD in treated and untreated cells was measured by immunoblot analysis. One of the first steps in the biosynthesis of cholesterol from acetic acid is catalyzed by MPD. As shown in Fig. 3A, the amount of MPD significantly de- 
A

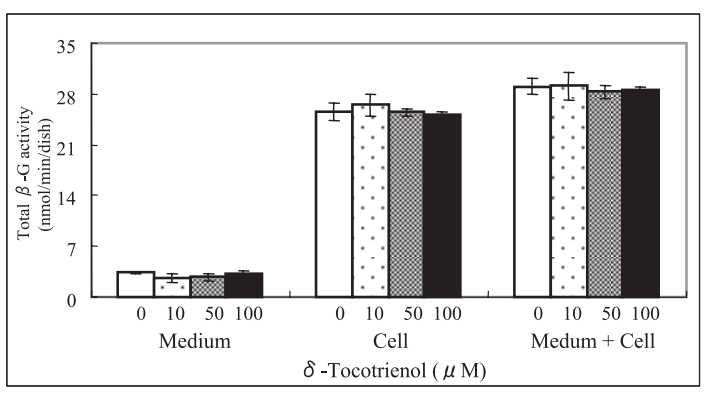

B

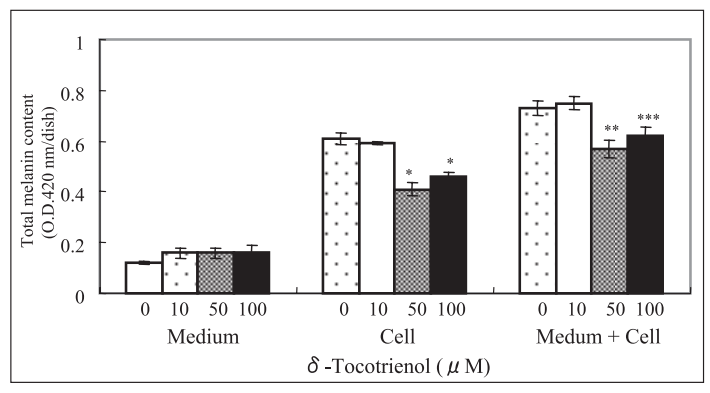

$\mathrm{C}$

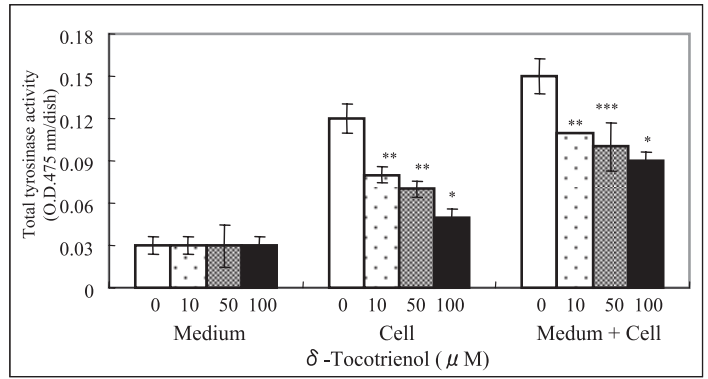

Fig. 2. Melanin Content and $\beta$-G Activity in Media of Cells Treated with $\delta$-Tocotrienol

$\beta-\mathrm{G}$ activity (A), melanin content (B) and tyrosinase activity (C) in media ( $1 \mathrm{ml})$ and cells $(750 \mu \mathrm{l})$ of dish were measured as described in Materials and Methods. Data are the means for three identical experiments. Significant differences: ${ }^{*} p<0.001,{ }^{* *} p<0.005,{ }^{* * *} p<0.05$.

creased in a dose-dependent manner on treatment with $\delta$-tocotrienol. The MPD level decreased by 20 , 31 , and $35 \%$ on treatment with 10,50 , and $100 \mu \mathrm{M}$ $\delta$-tocotrienol, respectively, compared with the level in control cells. These results suggested that $\delta$ tocotrienol lowered levels of cholesterol biosynthetic enzymes other than HMG-CoA reductase. However, the cholesterol content of cells treated with $10-100 \mu \mathrm{M} \delta$-tocotrienol for $24 \mathrm{hr}$ did not decrease significantly (Fig. 3B).

\section{DISCUSSION}

Results of the present study show that $\delta$ tocotrienol caused a decrease in the level of a cholesterol biosynthetic enzyme (MPD) other
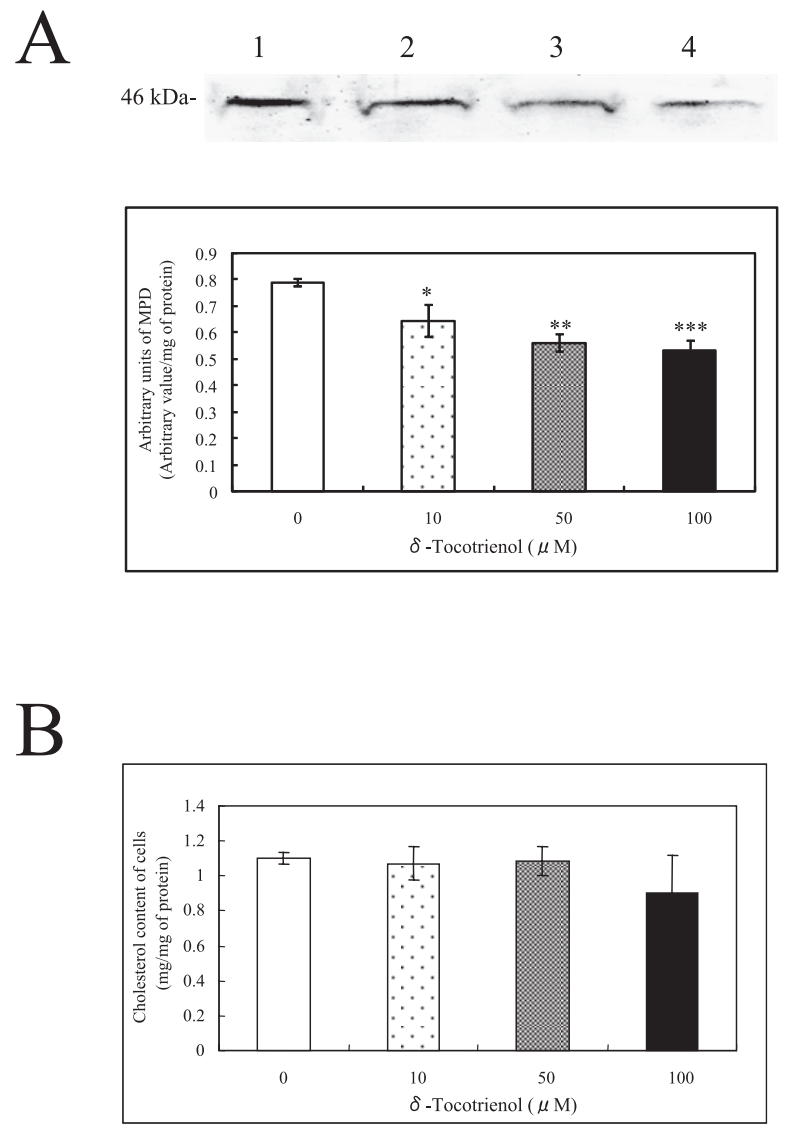

Fig. 3. Amount of MPD and Cholesterol Content in Cells Treated with $\delta$-Tocotrienol

Samples from the same PNS as those used in experiments shown in Fig. 1 were subjected to immunoblot analysis for MPD and cholesterol content. A: Signals for MPD in the immunoblot analysis were quantified using an Intelligent Quantifier. B: Cholesterol content was measured under the above conditions. Data are the means for three identical experiments. Significantly different: ${ }^{*} p<0.05,{ }^{* *} p<0.0005$, ${ }^{* * *} p<0.001$.

than HMG-CoA reductase (Fig. 3A). It was reported that $\delta$-tocotrienol effectively blocks cleavage and translocation to the Golgi of SREBP. ${ }^{25}$ ) $\delta$-Tocotrienol may have caused the decrease in MPD by promoting the ubiquitination and degradation of HMG-CoA reductase or inhibiting processing of SREBP-2. However, there was no change in the cholesterol content in cells treated with $\delta$ tocotrienol (Fig. 3B). These results suggested that B16 cells have a mechanism to maintain the appropriate cholesterol level despite the decrease in amount of cholesterol biosynthetic enzymes by $\delta$ tocotrienol, although the mechanism remains unclear. Therefore, $\delta$-tocotrienol does not appear to decrease the cholesterol contents.

We previously reported that the exocytosis of mature enzymes from lysosomes into the medium was caused by a lovastatin- and/or LDS-induced de- 
crease in the cholesterol content in $\mathrm{B} 16 \mathrm{~F} 10$ mouse melanoma cells. ${ }^{13)}$ We suggested that lysosomal exocytosis promotes the rapid repair of wounds in plasma membranes ruptured by a loss of cholesterol, as cholesterol is a major constituent of the plasma membrane. Therefore, it was suggested that not only lysosomes but also lysosome-related melanosomes were released by the decrease in cholesterol. However, the release of lysosomes and melanosomes was not caused by $\delta$-tocotrienol (Fig. 2), because $\delta$-tocotrienol did not decrease the cholesterol contents in the cells. Thus, $\delta$-tocotrienol does not mediate side effect cause the release of lysosomes and melanosomes.

In conclusion, $\delta$-tocotrienol may be useful as a therapeutic or preventive drug for hyperpigmentation and as a component of whitening and/or lightening cosmetics without side effects (reduction of cholesterol content and release of lysosomes/melanosomes), although $\delta$-tocotrienol cause a decrease of MPD.

\section{REFERENCES}

1) Sen, C. K., Khanna, S. and Roy, S. (2006) Tocotrienols: Vitamin E beyond tocopherols. Life Sci., 78, 2008-2098.

2) Brigelius Flohe, R. E. G. and Traber, M. G. (1999) Vitamin E: function and metabolism. FASEB J., 13, 1145-1155.

3) Qureshi, A. A., Pearce, B. C., Nor, R. M., Gapor, A., Peterson, D. M. and Elson, C. E. (1996) Dietary alpha-tocopherol attenuates the impact of gammatocotrienol on hepatic 3-hydroxy-3-methylglutaryl coenzyme A reductase activity in chickens. J. Nutr., 126, 389-394.

4) Qureshi, A. A., Bradlow, B. A., Brace, L., Manganello, J., Peterson, D. M., Pearce, B. C., Wright, J. J., Gapor, A. and Elson, C. E. (1995) Response of hypercholesterolemic subjects to administration of tocotrienols. Lipids, 30, 1171-1177.

5) Qureshi, A. A., Qureshi, N., Hasler Rapacz, J. O., Weber, F. E., Chaudhary, V., Crenshaw, T. D., Gapor, A., Ong, A. S., Chong, Y. H., Peterson, D. and Rapacz, J. (1991) Dietary tocotrienols reduce concentrations of plasma cholesterol, apolipoprotein $\mathrm{B}$, thromboxane B2, and platelet factor 4 in pigs with inherited hyperlipidemias. Am. J. Clin. Nutr., 53, 1042S-1046S.

6) Qureshi, A. A., Qureshi, N., Wright, J. J., Shen, Z., Kramer, G., Gapor, A., Chong, Y. H., Dewitt, G.,
Ong, A., Peterson, D. M. and Bradlow, B. A. (1991) Lowering of serum cholesterol in hypercholesterolemic humans by tocotrienols (palmvitee). Am. J. Clin. Nutr., 53, 1021S-1026S.

7) Qureshi, A. A., Burger, W. C., Peterson, D. M. and Elson, C. E. (1986) The structure of an inhibitor of cholesterol biosynthesis isolated from barley. $J$. Biol. Chem., 261, 10544-10550.

8) Theriault, A., Chao, J. T., Wang, Q., Gapor, A. and Adeli, K. (1999) Tocotrienol: a review of its therapeutic potential. Clin. Biochem., 32, 309-319.

9) Nesaretnam, K., Stephen, R., Dils, R. and Darbre, P. (1998) Tocotrienols inhibit the growth of human breast cancer cells irrespective of estrogen receptor status. Lipids, 33, 461-469.

10) Pearce, B. C., Parker, R. A., Deason, M. E., Qureshi, A. A. and Wright, J. J. (1992) Hypocholesterolemic activity of synthetic and natural tocotrienols. J. Med. Chem., 35, 3595-3606.

11) Pearce, B. C., Parker, R. A., Deason, M. E., Dischino, D. D., Gillespie, E., Qureshi, A. A., Volk, K. and Wright, J. J. (1994) Inhibitors of cholesterol biosynthesis. 2. Hypocholesterolemic and antioxidant activities of benzopyran and tetrahydronaphthalene analogues of the tocotrienols. $J$. Med. Chem., 37, 526-541.

12) Song, B. L. and DeBose-Boyd, R. A. (2006) Insig-dependent ubiquitination and degradation of 3-hydroxy-3-methylglutaryl coenzyme a reductase stimulated by delta- and gamma-tocotrienols. $J$. Biol. Chem., 281, 25054-25061.

13) Michihara, A., Toda, K., Suenobu, M., Akasaki, K. and Tsuji, H. (2007) Decrease of Cholesterol in Mouse Melanoma Causes Secretion of Lysosomal Enzymes. J. Biochem. (Tokyo), 141, 239-250.

14) Azarian, S. M., McLeod, I., Lillo, C., Gibbs, D., Yates, J. R. and Williams, D. S. (2006) Proteomic analysis of mature melanosomes from the retinal pigmented epithelium. J. Proteome Res., 5, 521529.

15) Diment, S., Eidelman, M., Rodriguez, G. M. and Orlow, S. J. (1994) Lysosomal Hydrolases Are Present in Melanosomes and Are Elevated in Melanizing Cells. J. Biol. Chem., 270, 4213-4215.

16) Jordens, I., Westbroek, W., Marsman, M., Rocha, N., Mommaas, M., Huizing, M., Lambert, J., Naeyaert, J. M. and Neefjes, J. (2006) Rab7 and Rab27a control two motor protein activities involved in melanosomal transport. Pigment Cell Res., 19, 412-423.

17) Michihara, A., Morita S., Hirokawa Y., Ago, S., Akasaki, K. and Tsuji, H. (2009) Delta-tocotrienol causes decrease of melanin content in mouse 
melanoma cells. J. Health Sci., 55, 314-318.

18) Lowry, O. H., Rosebrough, N. J., Farr, A. L. and Randall, R. J. (1951) Protein measurement with the Folin phenol reagent. J. Biol. Chem., 193, 265-275.

19) Robins, E., Hirsch, H. E. and Emmons, S. S. (1968) Glycosidases in the nervous system. I. Assay, some properties, and distribution of beta galactosidase, beta glucoronidadse, and beta glucosidase. J. Biol. Chem., 243, 4246-4252.

20) Hirosaki, K., Yamashita, T., Wada, I., Jin, H. Y. and Jimbow, K. (2002) Tyrosinase and Tyrosinase Related Protein 1 Require Rab7 for Their Intracellular Transport. J. Invest. Dermatol., 119, 475-480.

21) Lee, T. H., Lee, M. S. and Lu, M. Y. (1998) Effects of $\alpha \mathrm{MSH}$ on melanogenesis and tyrosinase of B 16 melanoma. Endocrinology, 91, 1180-1188.

22) Laemmil, U. K. (1970) Cleavage of structural pro- teins during the assembly of the head of bacteriophage T4. Nature., 227, 680-685.

23) Towbin, H., Staehelin, T. and Gordon, J. (1979) Electrophoretic transfer of proteins from polyacrylamide gels to nitrocellulose sheets: procedure and some applications. Proc. Natl. Acad. Sci. U.S.A., 76, 4350-4354.

24) Michihara, A., Sawamura, M., Nara, Y., Ikeda, K. and Yamori, Y. (1997) Purification and characterization of two mevalonate pyrophosphate decarboxylases from rat liver: a novel molecular species of 37kDa. J. Biochem. (Tokyo), 122, 647-654.

25) Song, B. L. and DeBose-Boyd, R. A. (2006) Insig-dependent ubiquitination and degradation of 3-hydroxy-3-methylglutaryl coenzyme a reductase stimulated by delta- and gamma-tocotrienols. $J$. Biol. Chem., 281, 25054-25061. 